\title{
PENGARUH MODEL PEMBELAJARAN KOOPERAATIF TIPE TGT (TEAM GAMES TOURNAMENT) TERHADAP PENGUASAAN KONSEP HUKUM HOOKE KELAS XI MIPA SMA NEGERI 51 JAKARTA
}

\author{
PRaisandy Aziz ${ }^{\text {a) }}$, Dwi Susanti ${ }^{\text {b) }}$, Raihanati ${ }^{\text {c) }}$ \\ Prodi Pendidikan Fisika, Fakultas Matematika dan Ilmu Pengetahuan Alam, Universitas Negeri Jakarta, Jalan \\ Rawamangun Muka No 1, Pulo Gadung, Kota Jakarta Timur, DKI Jakarta (13220) \\ Email: ${ }^{\text {a) }}$ raisandyaziz@gmail.com,${ }^{\text {b) }}$ dwi.susanti@gmail.com,${ }^{\text {c) }}$ raihanati57@gmail.com
}

\begin{abstract}
Abstrak
Penelitian ini bertujuan untuk menganalisa peningkatan kualitas nilai antara kelas yang menggunakan model Pembelajaran Kooperatif Tipe TGT (Team Games Tournament) dengan kelas Pembelajaran langsung (Direct Instruction) di SMA Negeri 51 Jakarta kelas XI MIPA. Metode penelitian ini menggunakan metode penelitian kuantitatif yang berfokus pada penguasaan konsep hukum Hooke dalam ilmu fisika dalam melihat pengaruh model pembelajaran kooperatif Tipe TGT. Hasil penelitian diuraikan menggunakan purposive sampling yang membandingkan selisih perbedaan 2 (dua) kelas yaitu kelas eksperimen melalui model pembelajaran Team Games Tournament dan kelas kontrol melalui model Pembelajaran Langsung pada siswa lalu mengukur tingkat kemampuan penguasaan konsep hukum hooke. Dari hasil penelitian ini menunjukkan peningkatan hasil belajar siswa dari kelas eksperimen yang terlihat lebih tinggi dibandingkan dengan kelas kontrol. Hal ini dibuktikan dari nilai rata-rata test akhir (post test) kelas eksperimen $=78,4$ dan kelas kontrol $=74,31$. Dari hasil posttest itu telah dilakukan tindakan berupa uji-t dan dapat diperoleh $\mathrm{t}_{\text {hitung }}=1,882$ dan $\mathrm{t}_{\mathrm{TABEL}}=1,717$, Melalui hasil uji-t bahwa $t_{\text {hitung }}>\mathrm{t}_{\mathrm{TABEL}}$, sehingga kesimpulannya $\mathrm{H}_{0}$ ditolak dan $\mathrm{H}_{\mathrm{a}}$ diterima. Sehingga dapat dikatakan model pembelajaran kooperatif tipe TGT (Team Games Tournament) terhadap penguasaan konsep Hukum Hooke dalam ilmu Fisika memiliki pengaruh terhadap hasil belajar siswa di SMAN 51 Jakarta.
\end{abstract}

Kata-kata kunci: Team Games Tournament, Hukum Hooke, SMAN 51 Jakarta

\section{PENDAHULUAN}

Proses belajar mengajar merupakan suatu proses yang mengandung serangkaian perbuatan guru dan siswa atas dasar hubungan timbal balik yang berlangsung dalam situasi edukatif untuk mencapai tujuan tertentu. Dengan kata lain proses belajar mengajar meliputi kegiatan yang dilakukan guru mulai dari perencanaan, pelaksanaan kegiatan sampai evaluasi dan program tindak lanjut yang berlangsung dalam situasi edukatif untuk mencapai tujuan tertentu dalam pengajaran. Kemampuan mengelola proses belajar mengajar adalah kesanggupan atau kecakapan peserta didik yang mencakup 
segi kognitif, afektif dan psikomotorik sebagai upaya mempelajari sesuatu berdasarkan perencanaan sampai dengan tahap evaluasi dan tindak lanjut agar tujuan pengajaran tercapai.

Salah satu komponen pembelajaran yang memiliki peranan penting dalam proses pembelajaran adalah media pembelajaran. Media pembelajaran merupakan sarana komunikasi yang berfungsiuntuk menyampaikan isi pesan pembelajaran kepada peserta didik, sehingga mampu memberikan rangsangan positif kepada siswa untuk belajar. Kurangnya penggunaan media pembelajaran di sekolah dapat menghambat kegiatan pembelajaran. Hal tersebut akan mempengaruhi hasil belajar siswa. Selain itu,media yang digunakan pada pembelajaran hendaknya lebih menarik, bermanfaat dan efektif.

Bedasarkan hasil penyebaran angket mengenai pemahaman pembelajaran fisika di kelas XI, masih terdapat siswa khususnya jurusan IPA yang menyatakan mengalami kesulitan dalam mempelajari fisika. Berdasarkan data tersebut, dapat diketahui bahwa siswa mengalami kesulitan dalam mempelajari fisika. Hal tersebut sesuai dengan hasil wawancara dengan guru fisika yang menyatakan bahwa hanya sebagian siswa yang tertarik dalam pembelajaran fisika. Artinya sebagian siswa lainnya kurang tertarik dengan pelajaran fisika dan masih mengalami kesulitan dalam mempelajari fisika. Hal ini dikarenakan proses pembelajaran yang monoton atau kurang variatif serta kurangnya pemanfaatan media pembelajaran dalam pembelajaran fisika.

Informasi lain yang diperoleh yaitu model pembelajaran yang masih menggunakan metode lama menjadikan siswa masih kurang dalam penguasaaan materimateri pelajaran khususnya Fisika. Penggunaan beberapa model pembelajaran baru sebenarna sudah diterapkan di sekolah dan sangat membantu proses pembelajaran, namun pemanfaatan bahan ajar di sekolah masih kurang sehingga mengakibatkan kurangnya penguasaan konsep pada siswa.

Berdasarkan hasil wawancara, diketahui bahwa sudah tersedia laboratorium komputer dan proyektor dengan keadaan baik, namun penggunaan model belajar yang efektif dalam pembelajaran fisika masih hanya sebatas pengenalan saja. Guru cendrung masih menggunakan modul yang menggunakan berbagai jenis media (teks, gambar, suara, video) yang digunakan untuk mengevaluasi jawaban siswa, menyediakan umpan balik, dan secara efektif akan meningkatkan motivasi siswa terutama dalam pembelajaran fisika. Pada materi Hukum Hooke misalnya, penyampaian materi tidak cukup dengan menggunakan buku siswa saja, tetapi memerlukan eksperimen, latihan soal, dan merumuskan ulang soalnya untuk penguasaan konsep fisika yang diperoleh.

Mempertimbangkan kemanfaatan model pembelajaran dan masalah-masalah yang dijelaskan di atas,maka diperlukan pengembangan model pembelajaran berbasis TGT yang menunjang proses pembelajaran. Oleh karena itu, penulis melakukan penelitian pengembangan dengan judul"Pengaruh Model Pembelajaran Kooperatif Tipe TGT (Team Games Tournament) Terhadap Penguasaan Konsep Hukum Hooke di Kelas XI SMA Negeri Jakarta”.

\section{METODOLOGI}

Tujuan dari penelitian ini adalah untuk mengukur "Pengaruh Model pembelajaran kooperatif tipe Teams Games Tournament (TGT) terhadap penguasaan konsep Hukum Hooke kelas XI SMA Negeri 51 Condet, Jakarta Timur". Penelitian ini dilaksanakan pada semester 1 (Ganjil) tahunpelajaran 2018/2019 dengan lama penelitian tiga bulan; mulai dari bulan April 2019 sampai dengan Mei 2019. Penelitian ini adalah penelitian kualitatif dengan desain pretest dan posttest yang dilakukan terhadap dua kelompok kelas, yaitu kelas eksperimen dan kelas kontrol. Dimana pada kelas eksperimen diterapkan pembelajaran dengan model pembelajaran kooperatif tipe Teams Games Tournament (TGT) dan pada kelas kontrol hanya diterapkan dengan pembelajaran biasa yaitu pembelajaran yang berpusat pada guru. Peneliti secara langsung melaksanakan proses pembelajaran dan penerapan model pembelajaran kooperatif tipe TGT. Sebelum dilaksanakan, kedua kelas terlebih dahulu, diberikan pretest dan perlakuan selanjutnya diberikan posttest. Dalam penelitian, peneliti menentukan populasi dan sampel. Populasi adalah wilayah generalisasi yang terdiri dari obyek atau subyek yang menjadi kuantitas dan karakteristik tertentu yang diterapkan oleh peneliti untuk 
dipelajari kemudian ditarik kesimpulannya (Supardi, 2013). Populasi dalam penelitian ini adalah siswa kelas XI SMA Negeri 51 Jakarta Timur.

Sampel adalah bagian dari populasi (sebagian atau wakil populasi yang diteliti) Sampel penelitian merupakan sebagian dari populasi yang diambil sebagai sumber data dan dapat mewakili seluruh populasi "Representative" (Supardi, 2013). Sampel penelitian ini adalah kelas XI MIPA 4 (kelas Kontrol) dan Kelas XI MIPA 3 (Kelas Eksperimen). Teknik pengambilan data yang dimaksud dalam penelitian ini adalah cara yang digunakan untuk memperoleh data-data empiris untuk mencapai tujuan penelitian. Cara yang digunakan peneliti dalam pengumpulan data adalah dengan menggunakan jenis test sebagai instrumen penelitian. Test tersebut di berikan secara langsung kepada dua kelompok sampel setelah peneliti memberikan perlakuan pada kedua kelompok tersebut. Tes yang digunakan dalam penelitian ini adalah tes awal (Pre-Test) dan Tes Akhir (Post-Test). Pre-Test adalah test sebelum menggunakan model pembelajaran kooperatif tipe Team Game Tournament (TGT) dalam pembelajaran yang bertujuan untuk mengetahui seberapa besar hasil belajar siswa sebelum diberikan perlakuan. Post-Test adalah test setelah menggunakan model pembelajaran kooperatif tipe Team Game Tournament (TGT) untuk melihat pengaruh hasil belajar siswa akibat adanya perlakuan. Untuk memperoleh butir tes yang mempunyai kategori baik dan bisa di pakai untuk penelitian, maka harus di uji cobakan terlebih dahulu. Analisis perangkat tes adalah analisis untuk mengetahui validitas, reliabilitas, indeks kesukaran dan daya pembeda.

Instrumen penelitian yang digunakan dalam penelitian ini adalah instrumen tes pilihan ganda (multiple choice test). Soal tes disusun berdasarkan ruang lingkup matri yang di ajarkan. Untuk keabsahan instrumen penelitian ada beberapa yang harus diperhatikan,antara lain : Validitas, Reabilitas, Indeks Kesukaran, Daya Pembeda. Teknik analisa data yang digunakan adalah melakukan uji normalitas data, melakukan uji homogenitas, Uji Hipotesis penelitian.

\section{HASIL DAN PEMBAHASAN}

\section{A. Pembelajaran Kooperatif Tipe Team Games Tournament (TGT) Pengertian Model Pembelajaran Kooperatif Tipe TGT}

Model pembelajaran Teams Games Tournament (TGT) sebagai salah satu tipe model pembelajaran kooperatif yang dapat diterapkan dalam proses pembelajaran IPS. Slavin (Abidin, 2014: 254) menyatakan bahwa TGT merupakan prosedur pembelajaran yang memberikan kesempatan kepada kelompok untuk berkompetisi dengan kelompok lain sehingga siswa bergairah belajar. Penerapan pembelajaran dalam TGT siswa memainkan permainan dengan anggota tim lain untuk memperoleh tambahan poin untuk skor tim mereka (Al- Tabani 2015: 131). Mulyatiningsih (2014: 244) TGT melibatkan aktivitas seluruh siswa tanpa harus ada perbedaan status, melibatkan peran siswa sebagai tutor teman sebaya dan mengandung unsur permainan dan penguatan.

Berdasarkan pendapat para ahli di atas, peneliti menyimpulkan bahwa model pembelajaran kooperatif tipe TGT adalah suatu pembelajaran yang menempatkan siswa kedalam kelompok belajar yang heterogen dan menerapkan unsur permainan turnamen dalam pembelajaran untuk memperoleh poin bagi skor tim.

\section{Kelebihan dan Kelemahan Model Pembelajaran Kooperatif Tipe TGT}

Penerapan model TGT dalam pembelajaran di kelas, memiliki beberapa kekurangan dan kelebihan. Berikut ini beberapa kelebihan dan kekurangan TGT, Taniredja (2012: 72 - 73).

Kelebihan TGT:

a. Dalam kelas kooperatif siswa memiliki kebebasan untuk berinteraksi dan menggunakan pendapatnya.

b. Rasa percaya diri siswa menjadi tinggi.

c. Perilaku mengganggu terhadap siswa lain menjadi lebih kecil.

d. Motivasi belajar siswa bertambah. 
e. Pemahaman yang lebih mendalam terhadap materi pelajaran.

f. Meningkatkan kebaikan budi, kepekaan, toleransi antara siswa dengan siswa dan antara siswa dengan guru.

g. Kerjasama antar siswa akan membuat interaksi belajar dalam kelas menjadi hidup dan tidak membosankan.

Kekurangan TGT:

a. Sering terjadi dalam kegiatan pembelajaran tidak semua siswa ikut serta menyumbangkan pendapatnya.

b. Kekurangan waktu untuk proses pembelajaran.

c. Kemungkinan terjadinya kegaduhan kalau guru tidak dapat mengelola kelas.

Berdasarkan pendapat para ahli di atas, dapat disimpulkan bahwa pembelajaran TGT memiliki beberapa kelebihan seperti menjadikan siswa lebih terlibat dalam pembelajaran, pemahaman lebih mendalam mengenai materi, siswa menjadi lebih semangat dalam pembelajaran,disamping itu pembelajaran TGT juga memiliki beberapa kelemahan yaitu, membutuhkan waktu yang cukup lama dalam penerapannya, memungkinkan terjadinya kegaduhan dalam kelas, dan menjadikan siswa terbiasa dengan adanya hadiah.

\section{Langkah-langkah Pembelajaran TGT}

Ada beberapa langkah dalam penggunaan model pembelajaran TGT yang perlu diperhatikan. Langkah-langkah penggunaan model Pembelajaran TGT. Menurut Slavin (2010: 106-7) terdapat lima komponen dalam TGT, yaitu presentasi kelas, tim, game, turnamen, dan rekognisi tim.

a. Presentasi kelas

Presentasi kelas digunakan guru untuk menyampaikan materi pelajaran melalui pengajaran langsung atau diskusi yang dipimpin oleh guru. Presentasi kelas juga dimanfaatkan guru untuk menyampaikan teknik pembelajaran yang akan digunakan, sehingga siswa dapat melaksanakan setiap kegiatan dalam langkah-langkah TGT dengan baik.

b. Kelompok (team)

Tim atau kelompok dalam TGT dibentuk berdasarkan keragaman kemampuan akademik siswa, yaitu kemampuan akademik tinggi, sedang, dan rendah. Fungsi utama dari tim ini yaitu memastikan bahwa semua anggota tim benar-benar belajar dan mempersiapkan anggotanya untuk dapat menjawab soal dengan baik pada saat turnamen.Setelah guru menyampaikan materi pelajaran, siswa berkumpul untuk mempelajari lembar kegiatan. Pembelajaran dalam tim mencakup pembahasan permasalahan bersama, membandingkan jawaban, dan mengoreksi tiap pemahaman apabila anggota tim ada yang membuat kesalahan.

c. Permainan (game)

Game atau permainan terdiri atas pertanyaan-pertanyaan yang dirancang untuk menguji pengetahuan siswa yang diperoleh dari presentasi kelas dan pelaksanaan kerja tim. Setiap siswa mewakili masing-masing tim untuk bermain game di atas meja turnamen. Dalam satu permainan terdiri dari kelompok pembaca, kelompok penantang I, kelompok penantang II, dan seterusnya sejumlah kelompok yang ada.

\section{d. Turnamen(tournament)}

Turnamen merupakan sebuah kegiatan berlangsungnya game, setelah guru memberikan presentasi di kelas dan tim telah berdiskusi membahas lembar kegiatan. Guru menempatkan siswa ke dalam meja turnamen. Siswa yang memiliki kemampuan akademik yang relatif sama duduk dalam meja turnamen yang sama untuk melakukan turnamen. Kompetisi yang seimbang ini memungkinkan siswa berkontribusi secara maksimal terhadap skor tim. Pada pelaksanaan turnamen, setiap siswa berusaha mendapatkan poin tertinggi di setiap meja turnamen. Poin yang mereka peroleh kemudian digabungkan dengan anggota lainnya yang berada pada meja turnamen yang berbeda untuk dijumlahkan menjadi skor tim. Penentuan tim yang menjadi pemenang dalam turnamen didasarkan pada banyaknya skor yang mereka peroleh.

e. Rekognisi Tim 
Tim akan mendapatkan sertifikat atau bentuk penghargaan lain apabila skor mereka mencapai kriteria tertentu. Penghargaan tim sangat penting untuk memberikan pengertian kepada siswa bahwa keberhasilan tim merupakan keberhasilan semua anggota tim, bukan semata-mata keberhasilan individu. Hal ini akan memotivasi siswa untuk membantu teman satu tim dalam belajar demi keberhasilan timnya.

Mulyatiningsih (2014: 245) langkah-langkah pembelajaran TGT secara runtut implementasinya terdiri dari 5 komponen, yaitu:

a. Penyajian Kelas

Pada awal pembelajaran guru menyampaikan materi dikelas, biasanya dilakukan dengan pengajaran langsung atau dengan ceramah dan tanya jawab

b. Pembentukan kelompok (team)

Satu kelompok terdiri dari 4-5 orang siswa yang anggotanya heterogen. Masing-masing kelompok diberi tugas untuk belajar bersama supaya semua anggota kelompok dapat memahami materi pelajaran dan dapat menjawab pertanyaan dengan optimal pada saat game dan tournamen mingguan.

c. Game

Guru menyiapkan pertanyaan (game) untuk menguji pengetahuan yang diperoleh siswa dari penyajian kelas dan belajar kelompok. Siswa memilih nomor game dan mencoba menjawab pertanyaan yang sesuai dengan nomor itu. Siswa yang dapat menjawab pertanyaan dengan benar akan mendapat skor, kemudian skor tersebut dikumpulkan untuk turnamen.

d. Turnamen

Turnamen dilakukan seminggu sekali atau setiap satu satuan materi pelajaran telah selesai dilaksanakan. Siswa melakukan permainan (game) akademik yaitu dengan cara berkompetisi dengan anggota tim yang memiliki kesamaan tugas / materi yang dipelajari. Guru menyiapkan beberapa meja turnamen. Setiap meja diisi tiga siswa yang memiliki kemampuan setara dari kelompok yang berbeda.

\section{e. Team recognize}

Team yang menunjukan kinerja paling baik akan mendapat penghargaan atau sertifikat. Seperti layaknya lomba, tim yang paling banyak mengumpulkan poin/ skor akan mendapat predikat juara umum, kemudian juara berikutnya berurutan sesuai dengan jumlah poin / skor yang berhasil diraihnya.

Dari dua pendapat ahli di atas, peneliti menerapkan langkah- langkah model pembelajaran kooperatif tipe TGT menurut pendapat Slavin. Karena langkah-langkah tersebut dijelaskan secara rinci pada tahapan-tahapan serta kegiatan-kegiatan yang dilaksanakan dalam mengimplementasikan model pembelajaran kooperatif tipe TGT. Selain itu, pembelajaran TGT dapat menambah semangat belajar dan rasa percaya diri siswa, menjadikan siswa aktif dalam proses pembelajaran, menjadikan pembelajaran lebih bermakna dan tidak monoton. Langkah-langkah pembelajaran TGT menurut Slavin (2010:106-7) yaitu sebagai berikut : a) Presentasi kelas, b) Kelompok (team), c) Permainan (game), d) Turnamen (tournament), e) Rekognisi tim.

\section{B. Hasil Penelitian}

\section{Analisis Data Hasil Belajar}

\subsection{Uji Normalitas}

a. Pengolahan Data Post-Test Kelas Eksperimen (XI MIPA 3)

Dari hasil pengolahan data, telah ditentukan distribusi frekuensi data pada TABEL $1 \mathrm{sbb}$ : TABEL 1 Distribusi Frekuensi Data untuk Nilai Post-Test Peserta didik Kelas

\section{Eksperimen}




\begin{tabular}{|c|c|c|c|c|c|c|c|}
\hline & Interval & & fi & xt & xt^2 & fi.xt & fi.xt $\mathbf{2}$ \\
\hline 58 & - & 62 & 1 & 60 & 3600 & 60 & 3600 \\
\hline 63 & - & 67 & 1 & 65 & 4225 & 65 & 4225 \\
\hline 68 & - & 72 & 1 & 70 & 4900 & 70 & 4900 \\
\hline 73 & - & 77 & 4 & 75 & 5625 & 300 & 22500 \\
\hline 78 & - & 82 & 9 & 80 & 6400 & 720 & 57600 \\
\hline 83 & - & 87 & 6 & 85 & 7225 & 510 & 43350 \\
\hline & & & & & & & \\
\hline & & & & & & & \\
\hline & total & & 22 & 435 & 31975 & 1725 & 136175 \\
\hline & rata-rata & & & & & $\mathbf{7 8 , 4 0 9 0 9 1}$ & \\
\hline
\end{tabular}

Sumber : Hasil Pengolahan Data (2019)

TABEL 2 Distribusi Frekuensi Uji Normalitas dari Nilai Post-test Peserta Didik Kelas Eksperimen

\begin{tabular}{|c|c|c|c|c|c|c|c|c|c|}
\hline$s^{\wedge} 2$ & s & fo & Batas Kelas & xbar & $\overline{Z i}$ & $\mathrm{~F}(\mathrm{zi})$ & Li & fe & (fo - fe)^2/fe \\
\hline \multirow{13}{*}{43,77706} & \multirow{6}{*}{6,616423} & 1 & 57,5 & \multirow{7}{*}{78,40909} & $-3,16018$ & 0,00078836 & \begin{tabular}{|l|}
0,007309 \\
\end{tabular} & 0,160804078 & 4,379551847 \\
\hline & & 1 & 62,5 & & $-2,40449$ & 0,00809763 & 0,041498 & 0,91294989 & 0,00830026 \\
\hline & & 1 & 67,5 & & $-1,64879$ & 0,04959536 & \begin{tabular}{|l|}
0,136308 \\
\end{tabular} & 2,998774668 & 1,332244205 \\
\hline & & 4 & 72,5 & & $-0,89309$ & 0,1859033 & 0,259454 & 5,707995855 & 0,511081282 \\
\hline & & 9 & 77,5 & & $-0,1374$ & 0,44535765 & 0,286452 & 6,301950206 & 1,155114283 \\
\hline & & 6 & 82,5 & & 0,618296 & 0,73180993 & \begin{tabular}{|l|}
0,183468 \\
\end{tabular} & 4,036293813 & 0,955367019 \\
\hline & & & 87,5 & & 1,373991 & 0,91527784 & & & \\
\hline & & & & & & & & & \\
\hline & & 22 & & & & & & $\mathrm{X}^{\wedge} 2$ hitung & 8,341658897 \\
\hline & & & & & & & & $\mathrm{x}^{\wedge} 2$ tabel & 11,07049769 \\
\hline & & & & & & & & & \\
\hline & & & & & & $\mathrm{X}^{\wedge} 2$ hitung & $\leq$ & $\mathrm{X}^{\wedge} 2$ tabel & \\
\hline & & & & & & \multicolumn{4}{|c|}{ DATA BERDISTRIBUSI NORMAL } \\
\hline
\end{tabular}

\section{Keterangan :}

Sumber : Hasil Pengolahan Data (2019)

$$
\text { fi = Banyaknya siswa }
$$

$\mathrm{xt}=$ Nilai Yang Diperoleh

$\mathrm{s}=$ Akar pangkat 2 dari total perhitungan $\mathrm{s}^{\wedge} 2$

$\mathrm{xi}=$ Batas Kelas

$\mathrm{xbar}=$ rata-rata batas kelas

$\mathrm{Zi}=\mathrm{Z}$-Score (Tabel Pembanding)

$\mathrm{F}(\mathrm{Zi})=$ Batas Luar Daerah

$\mathrm{Li}=$ Luas Daerah

$\mathrm{fe}=$ Frekuensi yang diharapkan

$(\text { fo }-\mathrm{fe})^{\wedge} 2 / \mathrm{fe}=$ Frekuensi Pengamatan $(\mathrm{Oi})$

Hasil perhitungan dari $\mathrm{x}^{2}$ hitung adalah 8,341658897 dan pengujian dilakukan menggunakan taraf signifikan 95\% $(\alpha=0,05)$ dan dengan derajat kebebasan $\mathrm{dk}=\mathrm{n}-1=6-1=5$, maka telah ditentukan TABEL distribusi chi kuadratnya adalah $\mathrm{x}^{2}{ }_{(0,05)(5)}=11,07049769$. Jadi kesimpulannya adalah $\mathrm{x}^{2}$ hitung $(8,314658897)<\mathrm{x}^{2}$ TABEL $(11,07049769)$ yang berarti bahwa hasil belajar peserta didik kelas eksperimen (XI MIPA 3) berdistribusi normal.

b. Pengolahan Data Post-Test Kelas Kontrol (XI MIPA 4)

Dari hasil pengolahan data yang telah dilakukan, telah diperoleh distribusi frekuensi data seperti pada TABEL $3 \mathrm{sbb}$ : 
TABEL 3 Distribusi Frekuensi Data untuk Nilai Post-Test Peserta Didik Kelas Kontrol

\begin{tabular}{|c|c|c|c|c|c|c|c|}
\hline \multicolumn{2}{|r|}{ Interval } & & $\mathrm{fi}$ & $\mathrm{xt}$ & $\mathrm{xt}^{\wedge} \mathbf{2}$ & fi.xt & fi.xt ${ }^{\wedge} 2$ \\
\hline 58 & & 62 & 3 & 60 & 3600 & 180 & 10800 \\
\hline 63 & & 67 & 1 & 65 & 4225 & 65 & 4225 \\
\hline 68 & & 72 & 3 & 70 & 4900 & 210 & 14700 \\
\hline 73 & & 77 & 7 & 75 & 5625 & 525 & 39375 \\
\hline 78 & $=$ & 82 & 5 & 80 & 6400 & 400 & 32000 \\
\hline 83 & & 87 & 3 & 85 & 7225 & 255 & 21675 \\
\hline \multirow{2}{*}{\multicolumn{3}{|c|}{ total }} & & & & & \\
\hline & & & 22 & 435 & 31975 & 1635 & 122775 \\
\hline & rata-rata & & & & & 74,3182 & \\
\hline
\end{tabular}

Sumber : Hasil Pengolahan Data (2019)

TABEL 4 Distribusi Frekuensi Uji Normalitas dari Nilai Post-Test Peserta Didik Kelas

Kontrol

\begin{tabular}{|c|c|c|c|c|c|c|c|c|c|}
\hline$s^{\wedge} 2$ & 5 & fo & Batas Kelas & xbar & $\mathrm{Zi}$ & $F(Z i)$ & Li & fe & (fo - fe $)^{\wedge} 2 / \mathrm{fe}$ \\
\hline \multirow{13}{*}{60,2273} & \multirow{6}{*}{7,76062} & 3 & 57,5 & \multirow{8}{*}{74,3182} & $-2,16712$ & 0,015113 & 0,04879 & 1,073303224 & 3,458631619 \\
\hline & & 1 & 62,5 & & $-1,52284$ & 0,0638995 & 0,12592 & 2,770243996 & 1,131223029 \\
\hline & & 3 & 67,5 & & $-0,87856$ & 0,1898196 & 0,21756 & 4,786386273 & 0,666719261 \\
\hline & & 7 & 72,5 & & $-0,23428$ & 0,4073827 & 0,25171 & 5,537677346 & 0,386152426 \\
\hline & & 5 & 77,5 & & 0,41 & 0,6590953 & 0,19503 & 4,290568559 & 0,117302162 \\
\hline & & 3 & 82,5 & & 1,05427 & 0,8541211 & 0,08764 & 1,927990968 & 0,596062629 \\
\hline & & & 86,5 & & 1,5697 & 0,9417571 & & & \\
\hline & & & & & & & & & \\
\hline & & 22 & & & & & & $\mathrm{X}^{\wedge} 2$ hitung & 6,356091126 \\
\hline & & & & & & & & $X^{\wedge} 2$ tabel & 11,07049769 \\
\hline & & & & & & & & & \\
\hline & & & & & & $X^{\wedge} 2$ hitung & $s$ & $X^{\wedge} 2$ tabel & \\
\hline & & & & & & DAT/ & BERDIS & TRIBUSI NOF & AAL \\
\hline
\end{tabular}

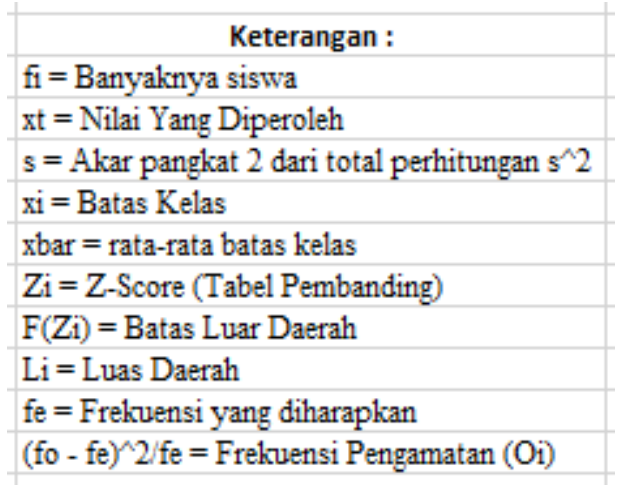

Sumber : Hasil Pengolahan Data (2019)

Hasil perhitungan dari $\mathrm{x}^{2}$ hitung adalah 6,356091126 dan pengujian dilakukan menggunakan taraf signifikan 95\% $(\alpha=0,05)$ dan dengan derajat kebebasan $\mathrm{dk}=\mathrm{n}-1=6-1=5$, maka telah ditentukan TABEL distribusi chi kuadratnya adalah $\mathrm{x}^{2}(0,05)(5)=11,07049769$. Jadi kesimpulannya adalah $\mathrm{x}^{2}$ hitung $(6,356091126)<\mathrm{x}^{2}$ TABEL $(11,07049769)$ yang berarti bahwa hasil belajar peserta didik kelas kontrol (XI MIPA 4) berdistribusi normal.

1.2 Uji Homogenitas Varian

Setelah menghitung dan menganalisis bahwa kedua sampel tersebut berdistribusi normal, Langkah selanjutnya akan diuji kembali nilai homogenitas menggunakan uji fisher. Uji Homogenitas berfungsi untuk mengetahui apakah sampel ini berhasil dari populasi dengan varians yang sama, sehingga hasil dari data penelitian ini berlaku untuk populasi. Dalam pengujian terdapat kriteria yang digunakan sebagai berikut :

Jika $\mathrm{F}_{\text {hitung }}<\mathrm{F}_{\mathrm{TABEL}}$ berarti kedua data homogen 
Jika $F_{\text {hitung }} \geq \mathrm{F}_{\text {TABEL }}$ berarti kedua data tidak homogen

TABEL 5 berikut ini merupakan TABEL uji homogenitas Post-Test pada kelas eksperimen dan kelas kontrol.

TABEL 5 Hasil Perhitungan Uji Homogenitas

\begin{tabular}{|c|c|c|c|c|}
\hline \multicolumn{3}{|c|}{ UOMOGENITAS POSTTEST } & \multirow[b]{2}{*}{5} & \multirow[b]{2}{*}{$s^{\wedge} 2$} \\
\hline Sampel & $\mathrm{N}$ & $\mathrm{dk}(\mathrm{N}-1)$ & & \\
\hline eksperimen & 22 & 21 & 6,61642 & 43,777056 \\
\hline kontrol & 22 & 21 & 7,76062 & 60,227273 \\
\hline Fhitung & 0,726864331 & & & \\
\hline Ftabel & 2,084188623 & & & \\
\hline Fhitung & $\leq$ & Ftabel & & \\
\hline & MOGEN & & & \\
\hline
\end{tabular}

\section{Sumber : Hasil Pengolahan Data (2019)}

Berdasarkan TABEL 5 diatas, hasil menunjukkan bahwa $F_{\text {hitung }}(0,726864331)<\mathrm{F}_{\text {TABEL }}$ $(2,084188623)$. Maka kesimpulannya adalah kedua varian tersebut homogen untuk data nilai PostTest.

\subsection{Uji Hipotesis}

Untuk menguji bagian hipotesis, digunakanlah statistik uji-t. Berikut ini terdapat rumusan hipotesis yang akan diujikan adalah sebagai berikut :

$\begin{array}{rlrl}\text { Ho }: \mu_{1} \leq \mu_{2}= & \text { Rata-rata hasil belajar hukum hooke siswa yang } \\ & \text { memperoleh model pembelajaran } & \text { Team } & \text { Games } \\ & \text { Tournament lebih kecil daripada siswa yang } \\ & \text { memperoleh model pembelajaran langsung } & & \\ = & \text { Rata-rata hasil belajar hukum hooke siswa yang } \\ & \text { memperoleh model pembelajaran Team } & \text { Games } \\ & \text { Tournament lebih besar daripada } & \text { siswa yang } \\ & \text { memperoleh model pembelajaran langsung }\end{array}$

Berikut ini adalah hasil pengolahan data penelitian yang akan ditampilkan pada TABEL 6:

TABEL 6 Hasil Pengolahan Data Penelitian

\begin{tabular}{|l|c|c|}
\hline \multicolumn{3}{|c|}{ UJI T DATA POSTTEST (HIPOTESIS) } \\
\hline \multicolumn{1}{|c|}{ Data Kelas } & Kelas Eksperimen & Kelas Kontrol \\
\hline Mean data tes akhir (xbar) & 78,4091 & 74,3182 \\
\hline Varian tes akhir (s^2) & 43,711 & 60,227 \\
\hline Standar deviasi tes akhir (s) & 6,61 & 7,76 \\
\hline jumlah siswa (n) & 22 & 22 \\
\hline t-tabel & $\mathbf{1 , 7 1 7}$ & \\
\hline t-hitung & $\mathbf{1 , 8 8 2 1 0 1 4 3 6}$ & \\
\hline \multicolumn{3}{|c|}{ t-hitung } \\
& Ha DITERIMA \\
\end{tabular}

Sumber: Data Hasil Penelitian Peserta Didik Kelas Eksperimen dan Kontrol (2019)

Pengujian hipotesis pada penelitian ini menggunakan data post-test peserta didik dengan menggunakan perhitungan rata-rata dan nilai standar deviasi pada kelas kontrol dan kelas eksperimen. Berdasarkan data diatas, telah dilihat pada TABEL distribusi t diperoleh nilai $\mathrm{t}_{\mathrm{TABEL}}=$ 1,717 dan diperoleh hasil $t_{\text {hitung }}=1,882101436$ dengan perhitungan taraf signifikan $\alpha=0,05$. Karena 
$\mathrm{t}_{\text {hitung }}(1,882101436)>\mathrm{t}_{\mathrm{TABEL}}(1,717)$ maka dapat ditarik kesimpulan bahwa model pembelajaran Team Games Tournament (TGT) dapat meningkatkan penguasaan konsep peserta didik terhadap materi Hukum Hooke kelas XI MIPA di SMAN 51 Jakarta.

\subsection{Peningkatan Penguasaan Konsep Peserta Didik}

Berdasarkan hasil yang telah diteliti diatas bahwa, melalui eksperimen model pembelajaran Team games Tournament (TGT) dapat dikatakan berpengaruh terhadap penguasaan konsep peserta didik dibandingkan melalui pembelajaran secara ceramah atau konvensional. Berikut TABEL penguasaan konsepnya :

TABEL 7 Penguasaan Konsep Peserta Didik Kelas Kontrol \& Kelas Eksperimen

\begin{tabular}{|l|c|c|}
\hline \multirow{2}{*}{\multicolumn{1}{|c|}{ Ranah Kognitif }} & \multicolumn{2}{|c|}{ Persentase Skor Rata-Rata } \\
\cline { 2 - 3 } & Kelas Kontrol & Kelas Eksperimen \\
\hline Pengetahuan (C1) & $79,09 \%$ & $81,82 \%$ \\
\hline Pemahaman (C2) & $78,40 \%$ & $85,23 \%$ \\
\hline Penerapan (C3) & $69,69 \%$ & $72,72 \%$ \\
\hline Analisis (C4) & $61,36 \%$ & $61,36 \%$ \\
\hline Sintesis (C5) & - & - \\
\hline Evaluasi (C6) & $86,36 \%$ & $93,18 \%$ \\
\hline
\end{tabular}

Sumber: Data Hasil Penelitian Peserta Didik Kelas Eksperimen dan Kelas Kontrol 2019

Berdasarkan TABEL 7 diatas, terlihat jelas bahwa terdapat adanya perbedaan penguasaan ranah kognitif mulai dari C1-C6 pada peserta didik antara kelas eksperimen dan kelas kontrol. Hal ini terjadi dikarenakan adanya pengaruh dari model pembelajaran tipe Team Games Tournament pada kelas eksperimen. Berikut penjelasannya melalui gambar :

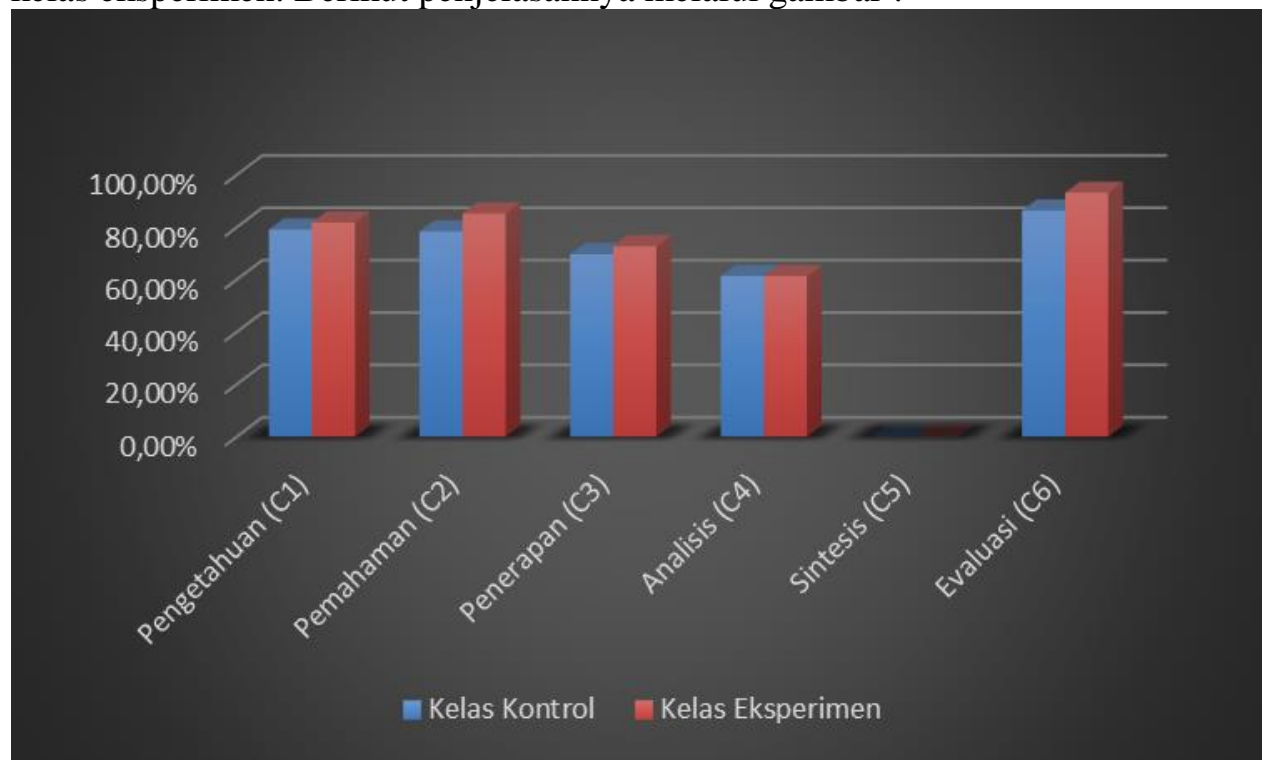

Gambar 1 Grafik Perbandingan Persentase Penguasaan Konsep Peserta Didik untuk Setiap Ranah Kognitif

Berdasarkan Gambar 4.7, terdapat perbedaan pada bagian penguasaan konsep di setiap ranah kognitif yaitu pada kelas eksperimen pada aspek Pengetahuan (C1) 81,82\% ; Pemahaman (C2) 85,23\% ; Penerapan (C3) 72,72\% ; Analisis (C4) 61,36\% ; Sintesis (C5) 0\% ; Evaluasi (C6) 93,18\%. Pada kelas kontrol aspek Pengetahuan (C1) 79,09\% ; Pemahaman (C2) 78,40\% ; Penerapan (C3) 69,69\% ; Analisis (C4) 61,36\% ; Sintesis (C5) 0\% ; Evaluasi (C6) 86,36\%. Seperti pada gambar grafik diatas. 


\section{SIMPULAN}

Berdasarkan tujuan penelitian dapat disimpulkan dari analisis data dan pembahasan hasil penelitian tentang pengaruh model pembelajaran TGT (Team Group Tournament) terhadap penguasaan konsep Hukum Hooke peserta didik pada materi hukum hooke peningkatan Penguasaan Konsep peserta didik berdasarkan pada kelas kontrol sebesar $46 \%$ dan kelas eksperimen sebesar 71 $\%$. Peningkatan sikap lebih besar terjadi pada kelas kontrol dengan model pembelajaran konvensional. Akan tetapi, bila ditinjau dari besar skor sikap peserta didik. Dari hasil postest di dapatkan hasil nilai di kelas kontrol 74.09\% dan kelas eksperimen sebenar 78\%. Sehingga, model pembelajaran Team Games Tournament (TGT) konsisten meningkatkan sikap peserta didik pada pembelajaran pertama dan kedua, lebih baik daripada model pembelajaran konvensional, ditinjau dari skor sikap peserta didik. Adapun saran dari peneliti untuk penelitian selanjutnya yaitu: Penelitian ini yang menjadi pokok bahasan adalah hukum hooke. Maka diharapkan bagi peneliti selanjutnya dapat menggunakan materi-materi lainnya dalam pembelajaran fisika. Penelitian dengan menggunakan model pembelajaran TGT (Team Group Tournament) yang lebih lama jika melakukan praktikum, dikarenakan peserta didik harus melakukan percobaan sesuai dengan model pembelajaran agar berhasil dalam menguasai konsep Hukum Hooke. Maka dari itu untuk peneliti selanjutnya yang ingin mengambil media pembelajaran menggunakan model TGT agar dapat menyesuaikan waktu dengan efektif dan efisien. TGT (Team Group Tournament) cocok digunakan dalam melakukan percobaan agar menguasai konsep pembelajaran, sehingga sangat disarankan untuk diterapkan dalam pembelajaran fisika yang memerlukan pratikum.

\section{REFERENSI}

[1] Anas Suditjono, 2010,Pengantar Statistik Pendidikan, (Jakarta: Rajawali Pers), hlm.298

[2] Bitar, 2019, "Hukum Hooke : Pengertian, aplikasi, bunyi dan Rumus beserta contohnya secara lengkap" diakses dari https://www.gurupendidikan.co.id//hukum-hooke-pengertian-aplikasi- bunyidan-rumus-beserta- contohnya-secara-lengkap/pada 08 februari 2019 pukul 20.19

[3] Christensen, L.B. (2001). Experimental Methodology (8th Ed.). Boston: Allyn and Bacon., hlm 65

[4] Cut Rauzah Tinur, 2017, "Pengaruh Model Pembelajaran Kooperatif Tipe Team Games Tournament terhadap peningkatan hasil belajar siswa pada pokok bahasan pesawat sederhana kelas VIII di SMPS Babul Maghfirah", Skripsi Prodi Pendidikan Fisika UIN Ar-Raniry, Darussalam Banda Aceh., hlm 2., diakses dari https://slidedocuments.org/philosophy-of-themoney.html?utm_source=skripsi-diajukan-oleh-cut-rauzah-tinur-nimmahasiswa-fakultas-tarbiyah-dan-keguruan-prodi-pendidikan-fisika ., pada tanggal 4 april 2018 pukul 8.00

[5] Ekocin, 2011, "Model Pembelajaran Teams Games Tournaments", diakses dari https://ekocin.wordpress.com/2011/06/17/modelpembelajaran-teams-games-tournaments-tgt-2/, pada tanggal 08 april 2018 pukul 21.49

[6] Fery Norcahyo, 2013, "Perbandingan Penggunaan Model Pembelajaran Team Games Tournament (TGT) Dengan Model Pembelajaran Student Teams Achievement Divisions (STAD) Terhadap Hasil Belajar Sejarah Kelas XI IPS 
[7] SMA Laboratorium UM Kota Malang", diakses dari http://karyailmiah.um.ac.id/index.php/sejarah/article/view/30147, pada tanggal 4 april 2018 pukul 8.26

[8] Kardi, Soeparman. Mohammad Nur. 2000. Pengajaran Langsung. Surabaya: Universitas Negeri Malang. hlm. 200

[9] Latipun, 2016, Psikologi Konseling ,(Malang: UMM Press) hlm 125 dan 128

[10]Linda Fikasari, Sri Utami, Sugiyono , 2015, "Pengaruh Kooperatif tipe Team Games Tournament Terhadap Hasil Belajar Pkn SDN 34 Pontianak", Jurnal program studi Pendidikan Dasar FKIP Untan., hlm 3., diakses dari jurnal.untan.ac.id/index.php/jpdpb/article/viewFile/17780/15142., pada tanggal 2 februari 2019 pukul 22.30

[11]Miftahul Huda, 2013,Model-model Pengajaran dan Pembelajaran,(Jakarta: Pustaka Belajar) .hlm.199

[12]Moch Ilham Sidik NH dan Hendri Winata , 2016, "Meningkatkan Hasil Belajar Siswa Melalui Penerapan Model Pembelajaran Direct Instruction", Jurnal program studi Pendidikan Manajemen Perkantoran FPEB., hlm 3 dan 4., diakses dari ejournal.upi.edu/index.php/jpmanper/article/download/3262/2317., pada tanggal 2 februari 2019 pukul 23.10

[13]Pasadea Amalia, 2018, "Keefektifan Model Pembelajaran Team Games Tournament (TGT) terhadap Peningkatan Hasil Belajar dan Sikap Peserta Didik Kelas $\mathrm{X}$ SMK N 1 Nanggulan”, Skripsi Prodi Pendidikan Fisika UNY, Yogyakarta.,Hlm 35., diakses dari eprints.uny.ac.id/55130/1/SKRIPSI\%20FULL.pdf ., pada tanggal 1 februari 2019 pukul 21.45.

[14]Sanjaya, W. (2007). Strategi Pembelajaran Berorientasi Sumber Proses Pendidikan. Jakarta Kencana

[15]Sahla Azzariya, 2015, "Bab 2 RPP Elastisitas dan Hukum Hooke" diakses dariwww.academia.edu/36488101/BAB_2_RPP_ELASTISITAS_DAN_HUKUM_H OOKE pada 08 februari 2019 pukul 22.10

[16]Sukardi,2005, Metodologi Penelitian Pendidikan, (Jakarta: Bumi Aksara), hlm 185.

[17]Supardi, 2013, Aplikasi Statistika dalam Penelitian, (Jakarta : Change Publication), Cetakan 1, hlm 22 dan 26

[18]Trianto. (2011).Model-model pembelajaran inovatif berorientasi konstruktivitis. Jakarta:Prestasi Pustaka. hlm 29 Wikipedia, "Hipotesis", diakses https://id.wikipedia.org/wiki/Hipotesis, pada tanggal 08 april 2018 pukul 22.38

[19]Ruseffendi, 1994, Statistika Dasar Untuk Penelitian Pendidikan, (Bandung: IKIP Bandung Pess), hlm. 132.

[20]Suharsimi Arikunto, 2009 Dasar-Dasar Evaluasi Pendidikan, (Jakarta: Bumi Aksara), hlm 100 dan 208

[21]Sudjana, 2005, Metoda Statistika, (Bandung: Tarsito), hlm. 263 
